\title{
Structural Volume of Hippocampus and Alzheimer's Disease
}

\section{INTRODUCTION}

Alzheimer's disease (AD) is a common and important disorder in which hippocampal atrophy is reported. It is the main neurodegenerative disease from aging, affecting about 5.2 million patients in the US with its prevalence expected to triple by the year 2050 . While the importance of hippocampal atrophy and Alzheimer's disease are unquestionably related, there is little knowledge on their predictive clinical progression.

Studies on the changes of hippocampal structures attest to changes in neuronal plasticity, myelination, and interneuronal connectivity, being an important disease. In the present scenario, in addition to symptoms suggestive of the disease, there are few quantitative data on macroscopic reference showing how the composition of the structure is affected. Currently, the primary basis of neuroimaging is the temporal medial atrophy score (MTA) or Scheltens Scale (Figure 1)2, prepared in 1995, which is obtained by visual analysis using MRI and coronal sections of the hippocampus T1 at the level of the anterior bridge, in which scores 0-4 indicate none to significant atrophy of the structure hippocampal and, in patients aged 75 or more, a score above 3 is considered abnormal ${ }^{3}$.

There are few studies that directly compare the predictive value of the measurements of the hippocampus and whole brain, most of which have inconsistent results. The majority of them compare hippocampal atrophy rates with measurements of total brain volume and baseline hippocampal volume in the same sample. There is not, to date, a paper documenting the average volume for the human species, a fact that encouraged the early search for determining a true value. Then, it would be possible to correlate and establish it as a development predictor of disease 
based on the hippocampal volume of each individual, compared to the average human and possible margins of anatomical variations of a normal hippocampus.

The importance of the study of the direct hippocampal volume follows the order in which brain regions are affected, according to the pathological and histological progression of Alzheimer's disease. Few studies have established the relationship between macroscopy and the hippocampus in Alzheimer's disease literature ${ }^{4,5}$, probably due to technical difficulties involved in this study area and in the absence of an established average volume structure found in humans.

\section{OBJECTIVES}

This study aimed to carry out a systematic review of international specialized literature, addressing the $\mathrm{AD}$ characteristics and confirming the existence of standard volume size of the hippocampus structure in humans and, thereby, establish the relationship between volumetry and values below average in healthy individuals who do not present cognitive decline. This would indicate a higher risk of developing Alzheimer's disease, thus determining another risk factor to be explored by science.

\section{METHODS}

The review was based on data found on Medline, PubMed, Scielo, Lilacs, periodicals portal of Higher Education Personnel Improvement Coordination
- CAPES and in Google Scholar national and international scientific articles published from 2000 to 2019 using as descriptors: Alzheimer's disease, Hippocampus, Volumetry Hippocampus, Hippocampal Volumetry.

Only English literature was selected. The eligibility criteria were studies that presented data relating to the disease disorders, gross brain lesions detected with MRI in software and segmentation, along with their control groups. We also included studies in which there was only the volumetric measurement of the hippocampus to determine the values that could establish a correlation of smaller hippocampal structure and risk of developing the disease.

\section{RESULTS}

During one year, Arlt et al. ${ }^{6}$ investigated the relationship between automated volumetric measurements and performance on neuropsychological tests in 50 patients with mild cognitive impairment (MCI), $\mathrm{AD}$, and control. They examined the relationship between the volume of different brain regions with the results of tests and found a strong correlation between the decrease in hippocampal volume and cognitive disorders.

A meta-analysis from 14 studies ${ }^{4}$, including a total of 365 patients with MCI and 382 controls, analyzed the extent of differentiated hippocampal atrophy in $\mathrm{AD}$ and MCI and evaluated the pattern of hippocampal volume asymmetry in control groups. The findings showed a bilateral loss of hippocampal volume in CCL

FIGURE 1

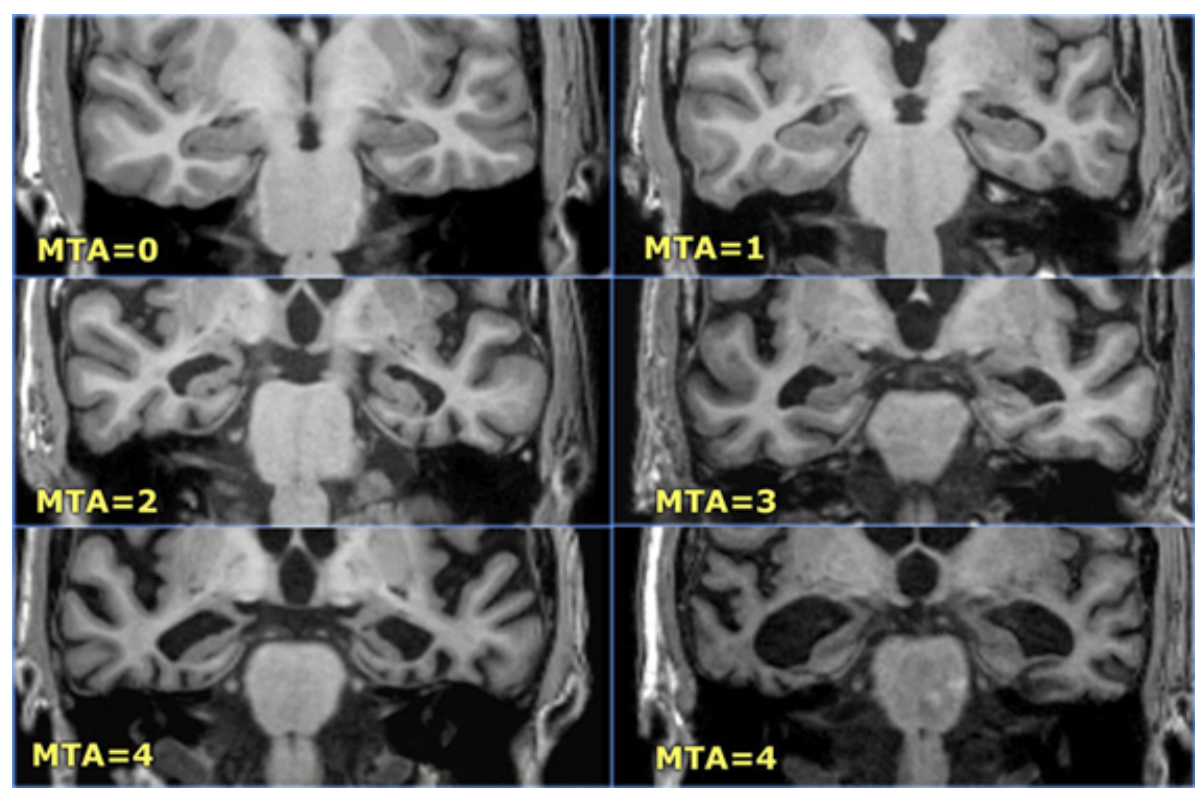


and a lower extent of atrophy than in AD. When comparing the volume of the left and right hippocampus, a pattern of consistent asymmetry, lower than the average was found, but with different levels of control between studies.

Martini et al. ${ }^{7}$ proposed a relationship between the volumes of the hippocampus and genetic influences in 170 healthy volunteers aged 46-77 years and revealed, in a lateralized analysis of the hippocampus, that the right hippocampus is, on average, slightly higher than the left in all age groups, and that hippocampal volume is slightly higher for women than men. In such an analysis, the mean volume was established based solely on the sample obtained.

The study by Yavuz et al. ${ }^{8}$ used manually measured volumes as the method of choice to assess the structures of 26 patients with $\mathrm{AD}, 22$ with MCI, and 15 with a healthy cognitive state. The hippocampal volume was normalized by the total brain volume and corrected by the size of the head. This study demonstrated the existence of a correlation between hippocampal atrophy, mild cognitive decline, and AD.

Recently, the Working Group EADC-ADNI on the Harmonized Protocol for the Hippocampus Manual segmentation and for Neuroimaging Initiative Alzheimer's Disease reported an average volume of 3.244 $\mathrm{cm} 3$ as normal in the healthy population with a mean age of 24 to 42 years old (40 patients) ${ }^{9}$.

Boccardi et al..$^{10}$ reported an average volume of the hippocampus (normalized to the intracranial volume) of $2.436 \mathrm{~cm} 3$ in normal aging, education average of 16 years, mean age 76 years; $1.804 \mathrm{~cm} 3$ in patients with $\mathrm{AD}$, education average of 15 years, mean age 76 years.

\section{DISCUSSION}

It is clear that scientific production based on hippocampal macroscopy, although existent for a long time, is still scarce. O'Brien ${ }^{11}$ has suggested, since 1995, that MRI of the temporal lobe has a sensitivity and specificity of $85 \%$ to $90 \%$ in the separation of clinically diagnosed ADs controls matched for age and seriously depressed patients.

Several publications based on the examination of structural neuroimaging typically assess brain structures compared to those of control groups, and there is no evaluation directed to healthy individuals (without mild cognitive impairment), using imaging as an intrinsic risk factor for disease development. It is certain that the temporal lobe volume assessed by RM imaging allows separating patients with mild $\mathrm{AD}$ from healthy controls, as occurred in the analysis of the above works. A total of 1070 individuals studied converged on the idea that hippocampal atrophy is already present in the CCL.

\section{CONCLUSIONS}

We may conclude that besides the great importance of clinical and epidemiological studies, any possibility of developing another predictive factor of development in previously healthy individuals is critical. Therefore it is proposed to carry out a prospective study in the general population on their hippocampal volumes to determine the hypothesis that a healthy person presents a smaller structure than the average human volumes and, thus, may have a higher chance of developing the disease in old age.

TABLE 1

\begin{tabular}{|c|c|c|}
\hline Authors & Measurement method and study $\mathrm{N}$ & Findings \\
\hline Shi et al. ${ }^{4}, 2009$ & $\begin{array}{l}\text { Meta-analysis of } 14 \text { studies, }(n=365 \\
\text { patients with DCL and } 382 \text { controls). } \\
\text { Variable Measurement Methods }\end{array}$ & $\begin{array}{l}\text { Bilateral loss of hippocampal volume in DCL and that the extent of } \\
\text { atrophy is less than in AD. }\end{array}$ \\
\hline Arlt et al. ${ }^{6}, 2013$ & $\begin{array}{l}\text { Automatic Volumetry } \\
(\mathrm{n}=50 \text {, age: } 45-95 \text { years })\end{array}$ & $\begin{array}{l}\text { Strong correlations between decreased hippocampal volume and } \\
\text { cognitive changes during one year of follow-up. }\end{array}$ \\
\hline Martini et al. ${ }^{7}, 2013$ & $\begin{array}{l}\text { Automatic Volumetry } \\
(\mathrm{n}=170)\end{array}$ & $\begin{array}{l}\text { The right hippocampus is slightly larger than the left (all age } \\
\text { groups). However, the mean volume was established based only on } \\
\text { the sample obtained. }\end{array}$ \\
\hline Yavuz et al. , 2007 & Volumetry Manual & Correlation between hippocampal atrophy with DCL and AD. \\
\hline Pruessner et al. ${ }^{9}, 2000$ & $\begin{array}{l}\text { Volumetry Manual } \\
(n=40)\end{array}$ & $\begin{array}{l}\text { Average volumes of } 3,244 \mathrm{~cm} 3 \text { as normal in a healthy population } \\
\text { with a mean age of } 24 \text { to } 42 \text { years. }\end{array}$ \\
\hline Boccardi et al. $^{10}, 2015$ & Volumetry Manual & $\begin{array}{l}\text { Develop a measurement standard; } \\
\text { They reported average volumes of the hippocampus: } \\
2,436 \mathrm{~cm}^{3} \text { in subjects with normal aging; } \\
1,804 \mathrm{~cm} 3 \text { in patients with AD. } \\
\text { From } 12 \text { protocols, reduced to } 4 \text { segmentation units to perform } \\
\text { Volumetry. }\end{array}$ \\
\hline
\end{tabular}




\section{Declaration of conflict of interest}

The authors declare no conflict of interest.

Financial support of the project
There was no financial support.

\section{Author's Contribution}

João Vitor Lois Balestrieri: dissertation, interpretation, and data analysis; Mahara Barbosa Nonato: dissertation, interpretation, and data analysis; Larissa Gheler: dissertation, interpretation, and data analysis; Mirto Nelso Prandini: guidance, and finalization

\section{RESUMO}

Pesquisas recentes demonstram que o hipocampo apresenta uma redução de volume no final da idade adulta, mantendo uma estreita relação com o declínio cognitivo. A aquisição da imagem por diversos métodos de medição de volume nos leva a encontrar na ressonância magnética o método de destaque, pois permite quantificar o volume de determinadas estruturas cerebrais utilizando a reconstrução computadorizada tridimensional das imagens obtidas.

OBJETIVOS: Confirmar a existência de diferenças entre o volume hipocampal e o declínio cognitivo leve, doença de Alzheimer e cognição normal.

MÉTODOS: Levantamento bibliográfico de estudos que apresentassem dados referentes aos distúrbios da doença de Alzheimer, alterações macroscópicas cerebrais detectadas com softwares na ressonância magnética e segmentação. Foram adicionados estudos apenas da medição volumétrica do hipocampo, objetivando-se chegar a valores que possam estabelecer uma correlação do menor valor estrutural hipocampal e risco de desenvolvimento da doença.

RESULTADOS: Um total de 1.070 indivíduos foi analisado em seis estudos clínicos, demonstrando a relação da diminuição do hipocampo na neuroimagem, correlacionado com o comprometimento cognitivo leve e doença de Alzheimer.

CONCLUSÕES: O desenvolvimento de um valor padrão para esse fim seria bastante útil na coleta de dados, permitindo melhor compreensão de algumas alterações que podem ocorrer na cognição, determinar valores prognósticos e até, em um futuro próximo, fator de risco imagiológico para a doença.

PALAVRAS-CHAVE: Hipocampo. Espectroscopia de ressonância magnética. Titulometria. Doença de Alzheimer.

\section{REFERENCES}

1. Dhikav $\bigvee$, Anand K. Potential predictors of hippocampal atrophy in Alzheimer's disease. Drugs Aging. 2011;28(1):1-11.

2. Barkhof F, Hazewinkel M, Binnewijzend M, Smithuis R. Brain - Dementia: role of MRI updated version. Neuroradiology course for the Dutch Society of Radiology; 2012. [cited 2019 Aug 02]. Available from: https://radiologyassistant.nl/neuroradiology/brain-dementia-role-of-mri

3. Scheltens P, Launer LJ, Barkhof F, Weinstein HC, van Gool WA. Visual assessment of medial temporal lobe atrophy on magnetic resonance imaging: interobserver reliability. J Neurol. 1995;242(9):557-60.

4. Shi F, Liu B, Zhou Y, Yu C, Jiang T. Hippocampal volume asymmetry in mild cognitive impairment and Alzheimer's disease: meta-analyses of MRI studies. Hippocampus. 2009;19(11):1055-64.

5. Hill DLG, Schwarz AJ, Isaac M, Pani L, Vamvakas S, Hemmings R, et al. Coalition against major disease/European Medicines Agency biomarker qualification hippocampal volume enrichment clinical trials in predementia stages of Alzheimer's disease. Alzheimers Dement. 2014;10(4):421-9.

6. Arlt S, Buchert R, Spies L, Eichenlaub M, Lehmbeck JT, Jahn H. Association between fully automated MRI-based volumetry of different brain regions and neuropsychological test performance in patients with amnestic mild cognitive impairment and Alzheimer's disease. Eur Arch Psychiatry Clin Neurosci. 2013;263(4):335-44.

7. Martini LLL. Medição manual da volumetria do hipocampo utilizando o visualizador Osirix ${ }^{\oplus}$ [Dissertação de Mestrado]. Brasília: Universidade de Brasília; 2013. 61p.

8. Yavuz BB, Ariogul S, Cankurtaran M, Oguz K, Halil M, Dagli N, et al. Hippocampal atrophy correlates with the severity of cognitive decline. Int Psychogeriatr. 2007;19(4):767-77.

9. Pruessner JC, Li LW, Serles W, Pruessner M, Collins DL, Kabani N, et al. Volumetry of hippocampal and amygdala with high-resolution MRI and three-dimensional analysis software: minimizing the discrepancies between laboratories. Cereb Cortex. 2000;10(4):433-42.

10. Boccardi M, Bocchetta M, Ganzola RN, Robitaille N, Redolfi A, Duchesne S, et al. EADC-ADNI Working Group on The Harmonized Protocol for Manual Hippocampal Segmentation and for the Alzheimer's Disease Neuroimaging Initiative. Operationalizing protocol differences for EADC-ADNI manual segmentation. Alzheimers Dement. 2015;11(2):184-94.

11. O'Brien JT. Is hippocampal atrophy on magnetic resonance imaging a marker for Alzheimer's disease? Int J Geriatr Psychiatry. 1995;10(6):431-5. 